\title{
Sox9 is a $\beta$-catenin-regulated transcription factor that enhances the colony-forming activity of squamous cell carcinoma cells
}

\author{
XUE MEI LI ${ }^{*}$, YONG JUN PIAO ${ }^{2 *}$, KYUNG-CHEOL SOHN ${ }^{3}$, JEONG-MIN HA $^{3}$, MYUNG IM $^{3}$, \\ YOUNG-JOON SEO ${ }^{3}$, KYU UANG WHANG ${ }^{4}$, JEUNG-HOON LEE ${ }^{3}$, YOUNG LEE $^{3}$ and CHANG DEOK KIM ${ }^{3}$ \\ ${ }^{1}$ Department of Dermatology, Taihe Hospital, Hubei University of Medicine, Shiyan, Hubei 442000; \\ ${ }^{2}$ Department of Dermatology, The First Affiliated Hospital of Dalian Medical University, \\ Dalian, Liaoning 116044, P.R. China; ${ }^{3}$ Department of Dermatology, School of Medicine, \\ Chungnam National University, Daejeon 301-747; ${ }^{4}$ Department of Dermatology, \\ College of Medicine, Soonchunhyang University, Seoul 330-721, Republic of Korea
}

Received June 30, 2015; Accepted April 8, 2016

DOI: $10.3892 / \mathrm{mmr} .2016 .5210$

\begin{abstract}
Squamous cell carcinoma (SCC) is a common skin cancer, of which the incidence is relatively high, ranking second among the non-melanoma skin cancers. It is known that numerous intracellular signal regulators are involved in the pathogenesis of SCC. The Wnt/ $\beta$-catenin signaling pathway serves an important role in cancer development. However, the downstream effectors of $\beta$-catenin remain to be clearly elucidated yet. The present study investigated the functional importance of $\mathrm{Wnt} / \beta$-catenin signaling in cutaneous SCC. $\beta$-catenin expression was reduced using recombinant adenovirus expressing specific microRNA (miR). Knockdown of $\beta$-catenin resulted in a marked reduction of the colony-forming activity of the SCC cells, SCC12. In an attempt to identify the $\beta$-catenin downstream genes, it was found that Sox 9 was regulated by $\beta$-catenin in SCC12 cells. Overexpression of a constitutively active form of $\beta$-catenin led to the induction of Sox9, while knockdown of $\beta$-catenin resulted in downregulation of Sox9. When the expression of Sox9 was reduced using specific miR, colony-forming activity of the SCC12 cells was significantly reduced. When Sox 9 was overexpressed in cells where $\beta$-catenin was knocked down, it partially restored the colony-forming potential. Taken together, the present results suggested that Sox 9 is a $\beta$-catenin downstream transcription factor and is positively involved in SCC development.
\end{abstract}

Correspondence to: Professor Chang Deok Kim, Department of Dermatology, School of Medicine, Chungnam National University, 266 Munhwa-ro, Jung-gu, Daejeon 301-747, Republic of Korea

E-mail: cdkimd@cnu.ac.kr

*Contributed equally

Key words: $\beta$-catenin, Sox9, squamous cell carcinoma

\section{Introduction}

Squamous cell carcinoma (SCC) is a common skin cancer originating from the upper layers of skin epidermis. The incidence of SCC is relatively high, ranking second among the non-melanoma skin cancers (1). Numerous factors are implicated in the pathogenesis of SCC, of which ultraviolet (UV) radiation is regarded as the most important environmental risk factor. UV radiation induces DNA damage and mutations of numerous susceptible genes, including the tumor suppressor, p53 (2). In addition, several intracellular signal regulators are involved in cancer development and progression. Examples include epidermal growth factor receptor, nuclear factor- $\kappa$-light-chain-enhancer of activated B cells and the Wnt/ $\beta$-catenin signaling pathways (3-7).

In canonical Wnt $/ \beta$-catenin signaling, binding of Wnt ligands to their cognate membrane receptors leads to the inactivation of the $\beta$-catenin degradation complex, resulting in the stabilization of cytoplasmic $\beta$-catenin. Once accumulated, $\beta$-catenin locates to the nucleus and interacts with the Lef-1/TCF family of DNA-binding proteins to generate a functional transcription factor complex (8). The pivotal role of Wnt/ $\beta$-catenin signaling in cancer development has been previously described (9-11). The importance of $\beta$-catenin in skin cancer is supported by the fact that epidermis-specific ablation of the $\beta$-catenin gene results in the loss of cancer initiating cells and complete tumor regression (12). In addition, a previous genetic study showed that chromosome loci harboring Wnt signaling genes are frequently amplified in SCC (13), indicating a potential importance of Wnt/ $\beta$-catenin signaling in cutaneous SCC.

Although the pivotal role of $\mathrm{Wnt} / \beta$-catenin signaling in SCC is well recognized, the downstream effectors of $\beta$-catenin remain to be clearly elucidated. The present study identified Sox9 as a $\beta$-catenin-regulated gene and demonstrated that Sox9 has a potential role in the regulation of SCC cells.

\section{Materials and methods}

Cell culture. The SCC12 human squamous cell carcinoma cell line was provided by Professor Tae-Jin Yoon (Gyeongsang 
National University, Jinju, South Korea) and maintained in Dulbecco's modified Eagle's medium (DMEM), supplemented with $10 \%$ fetal bovine serum (FBS; Thermo Fisher Scientific, Inc., Waltham, MA, USA). Human keratinocytes were isolated from skin specimens then immortalized using a recombinant retrovirus expressing Simian virus 40 large T antigen (SV40T), as described in a previous report (14). SV40T-transformed human epidermal keratinocytes (SV-HEK) were maintained in keratinocyte-serum free medium (Thermo Fisher Scientific, Inc.), supplemented with bovine pituitary extract and recombinant human epidermal growth factor (Thermo Fisher Scientific, Inc.) (14). Human dermal fibroblasts were primary cultured and maintained in DMEM, supplemented with $10 \%$ FBS. Human melanocytes were cultured in Medium 254 (Cascade Biologics, Portland, OR, USA) and human melanocyte growth supplement (Cascade Biologics) $(15,16)$. Cells were maintained at $37^{\circ} \mathrm{C}$ in an atmosphere $5 \% \mathrm{CO}_{2}$ and $90 \%$ relative humidity.

Immunohistochemistry. All human skin samples were obtained under the written informed consent of donors, in accordance with the Ethical Committee approval process of the Institutional Review Board of Chungnam National University School of Medicine. Paraffin sections of skin specimens were dewaxed, rehydrated and washed three times with phosphate-buffered saline (PBS). The tissue sections were subsequently incubated with proteinase $\mathrm{K}$ (Dako, Carpinteria, CA, USA) for $5 \mathrm{~min}$ at $37^{\circ} \mathrm{C}$, and treated with $\mathrm{H}_{2} \mathrm{O}_{2}$ for $10 \mathrm{~min}$ at room temperature. The tissue sections were blocked in $0.1 \%$ Tween-20 and $1 \%$ bovine serum albumin (Sigma-Aldrich, St. Louis, MO, USA) in PBS for $30 \mathrm{~min}$. Following blocking, the tissue sections were incubated at $4{ }^{\circ} \mathrm{C}$ with the appropriate primary antibodies as follows: Rabbit polyclonal anti- $\beta$-catenin (1:100 dilution; cat. no. sc-7199; Santa Cruz Biotechnologies, Inc., Santa Cruz, CA, USA); mouse monoclonal anti-Sox9 (1:200 dilution; cat. no. ab76997; Abcam, Cambridge, MA, USA) overnight. Subsequently, the tissue sections were incubated with the following peroxidase-conjugated secondary antibodies (dilution, 1:1,000): Horseradish peroxidase (HRP)-conjugated polyclonal goat anti-rabbit immunoglobulin (Ig; cat. no. P0448) and HRP-conjugated polyclonal rabbit anti-mouse Ig (cat. no. P0161; both Dako), visualized using 3,3'-diaminobenzidine solution from the Chemmate envision detection kit (Dako) and photographed under a Diaphot inverted microscope (Nikon Corporation, Tokyo, Japan).

Western blot analysis. The cells were lysed in Proprep solution (Intron, Daejeon, Korea). The total protein was quantified using a bicinchoninic acid protein assay reagent (Pierce Biotechnology, Inc., Rockford, IL, USA). The samples were separated by $10 \%$ sodium dodecyl sulfate-polyacrylamide gel electrophoresis ( $100 \mathrm{~V}$ for $1 \mathrm{~h}$ ) and transferred onto nitrocellulose membranes (Thermo Fisher Scientific, Inc.). The membranes were then blocked using 5\% skimmed milk in Tris-buffered saline and Tween-20 (Sigma-Aldrich) for $1 \mathrm{~h}$ at room temperature, and incubated (for $1 \mathrm{~h}$ at room temperature) with mouse monoclonal anti-Sox9 (1:200 dilution), rabbit polyclonal anti- $\beta$-catenin (1:100 dilution) and mouse monoclonal anti- $\beta$-actin [1:1,000 dilution (cat. no. A2228), Sigma-Aldrich] primary antibodies. Following primary antibody incubation, the membranes were incubated for $1 \mathrm{~h}$ at room temperature with the following secondary antibodies: Rabbit anti-mouse IgG (cat. no. ab97046) and goat anti-rabbit IgG (cat. no. .ab6721; both Abcam) and were visualized by enhanced chemiluminescence (Intron).

Production of recombinant adenovirus. The recombinant adenovirus expressing an 87-amino acid N-terminally truncated $\beta$-catenin $(\mathrm{Ad} / \Delta \mathrm{N} 87-\beta$-cat) or Sox9 (Ad/Sox9) were previously described $(17,18)$. For knockdown experiments, the recombinant adenovirus expressing microRNA (miR) was generated. The target sequences for $\beta$-catenin and Sox 9 were designed using BLOCK-iT ${ }^{\mathrm{TM}}$ RNAi Designer (Thermo Fisher Scientific, Inc.). The double-stranded DNA oligonucleotides were synthesized and cloned into the parental vector, pcDNA6.2-GW (Thermo Fisher Scientific, Inc.). In this vector system, the miR sequence for the target gene is located downstream of emerald green fluorescent protein (EmGFP) coding sequence, allowing the identification of miR expressing cells by observing GFP under an IX71 fluorescent microscope (Olympus Corporation, Tokyo, Japan). This vector was termed pcDNA6.2-GW/EmGFP-miR. The expression cassette for miR was moved into the $\mathrm{pENT/CMV}$ vector and then adenovirus was generated. The miR sequences were as follows: $\beta$-catenin, top strand: 5'-TGCTGTCTGCATGCCCTCATC TAATGGTTTTGGCCACTGACTGACCATTAGATGGGC ATGCAGA-3' and bottom strand: 5'-CCTGTCTGCATGCC CATCTAATGGTCAGTCAGTGGCCAAAACCATTAGAT GAGGGCATGCAGAC-3'; Sox9, top strand: 5'-TGCTGTGTT CTTGCTGGAGCCGTTGAGTTTTGGCCACTGACTGAC TCAACGGCCAGCAAGAACA-3' and bottom strand: 5'-CCT GTGTTCTTGCTGGCCGTTGAGTCAGTCAGTGGCCAA AACTCAACGGCTCCAGCAAGAACA-3'C. For adenovirus transduction, SCC12 cells were incubated with 10 multiplicity of infection of adenovirus for $6 \mathrm{~h}$ at $37^{\circ} \mathrm{C}$ in an atmosphere $5 \%$ $\mathrm{CO}_{2}$ and $90 \%$ relative humidity. The cells were replenished with fresh medium and incubated for a further 2 days.

Colony forming assay. The cells were trypsinized and counted using a hemocytometer. Following counting, $\sim 1,000$ cells were resuspended in DMEM, supplemented with $10 \% \mathrm{FBS}$, and were seeded into $100 \mathrm{~mm}$ culture dishes. The cells were incubated for 2-3 weeks and stained with crystal violet (Sigma-Alrdrich).

Statistical analysis. The data were statistically analyzed using one-way analysis of variance with SPSS software (v22.0; IBM SPSS, Chicago, IL, USA). $\mathrm{P}<0.01$ was considered to indicate a statistically significant difference.

\section{Results}

In order to elucidate the importance of $\beta$-catenin in cutaneous SCC, the present study first determined the expression of $\beta$-catenin by immunohistochemistry. In normal skin, $\beta$-catenin immunoreactivity was observed in all epidermal layers, with a characteristic membrane staining pattern. In SCC, very intense immunostaining of $\beta$-catenin was observed, and notably, many of the SCC cells exhibited nuclear staining of $\beta$-catenin (Fig. 1A). These results suggested a fundamental role of $\beta$-catenin signaling in cutaneous SCC. The relative expression level of $\beta$-catenin in SCC12 cell line and skin-comprising 
A

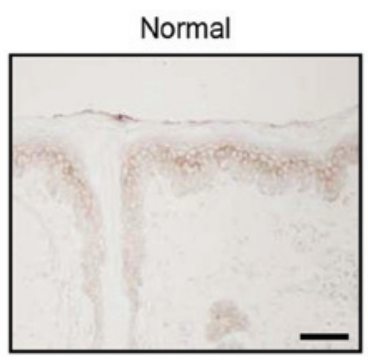

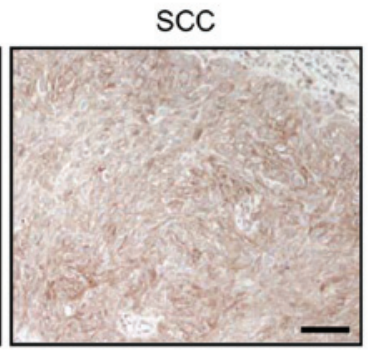

B

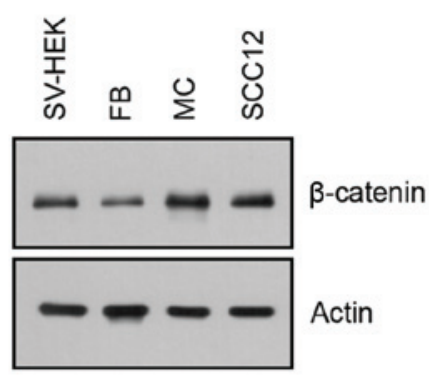

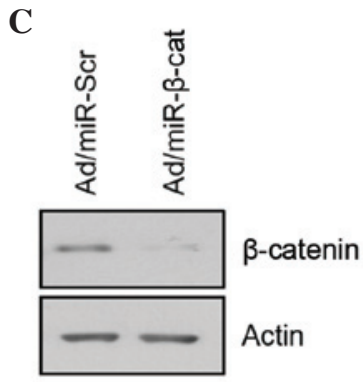

D
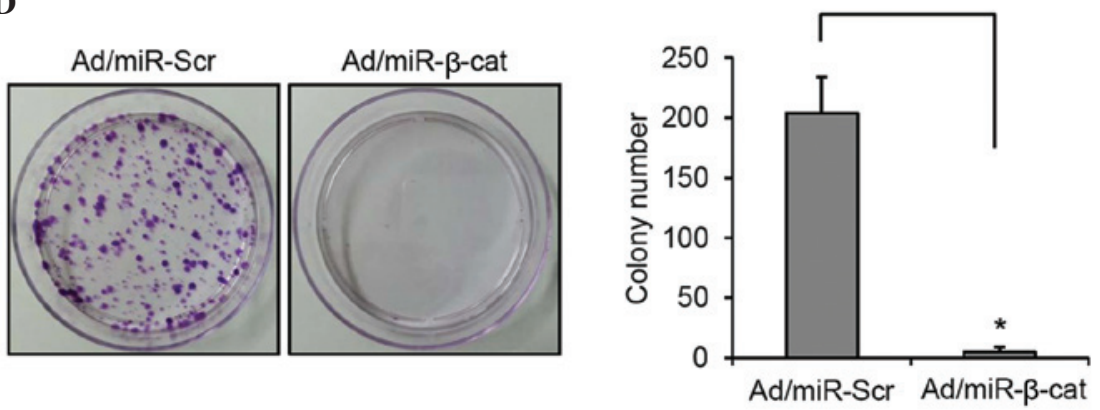

Figure 1. Expression and role of $\beta$-catenin in SCC. (A) Immunohistochemistry analysis of $\beta$-catenin expression in normal skin and cutaneous SCC. In SCC, intense immunoreactivity was observed in both the membrane and nuclei (scale bar, $100 \mu \mathrm{m}$ ). (B) The protein expression of $\beta$-catenin in cultured skin cells was determined by western blotting. Actin was used as a loading control. (C) The SCC12 cells were transduced with Ad/miR- $\beta$-cat. Western blotting revealed effective knockdown of $\beta$-catenin. Ad/miR-Scr was used for negative control and actin was used as a loading control. (D) A colony-forming assay was performed after Ad transduction. The SCC12 cells were cultured for 2 days, treated with trypsin/EDTA, re-suspended and seeded at a low concentration. The cells were cultured for 2 weeks and stained with crystal violet. Colonies were counted. The data are expressed as the mean \pm standard deviation $\left(\mathrm{n}=3\right.$; $\left.{ }^{*} \mathrm{P}<0.01\right)$. SCC, squamous cell carcinoma; SV-sHEK, simian virus 40 large T antigen-transformed human epidermal keratinocytes; FB, dermal fibroblasts; MC, melanocytes; miR, microRNA; Ad, adenovirus; Scr, scrambled; $\beta$-cat, $\beta$-catenin.

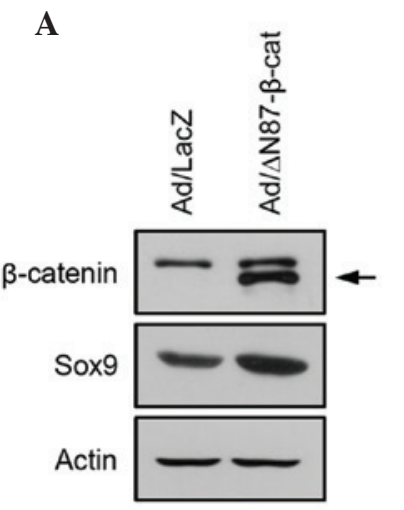

C

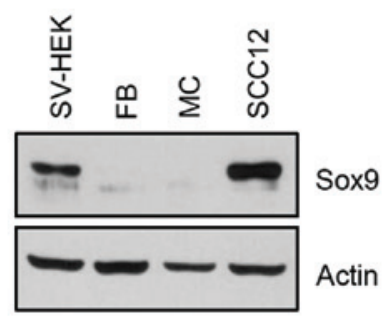

B

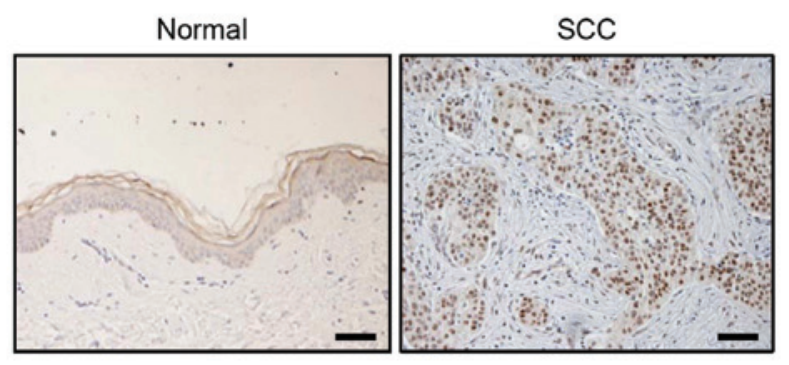

D

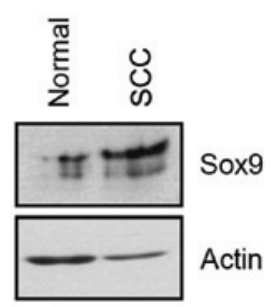

Figure 2. Identification of Sox9 as a $\beta$-catenin-regulated gene in SCC12 cells. (A) SCC12 cells were transduced with Ad expressing a constitutively active form of $\beta$-catenin $(\Delta \mathrm{N} 87)$ and/or miR specific for $\beta$-catenin. Exogenous $\mathrm{N}$-terminal truncated $\beta$-catenin (arrow) was detected. Following the activation and/ or repression of $\beta$-catenin, the expression of Sox 9 was determined by western blotting. Ad expressing LacZ and/or miR-scr were used as negative controls. Actin was used as a loading control. (B) Immunohistochemical analysis of the expression of Sox9 in normal skin and cutaneous SCC tissues. In SCC, intense immunoreactivity is seen in the nucleus (scale bar, $100 \mu \mathrm{m}$ ). (C) The expression of Sox9 in normal skin tissue and SCC tissue was confirmed by western blotting. Actin was used as a loading control. (D) The expression levels of Sox9 in cultured skin cells were confirmed by western blotting. Actin was used as a loading control. Ad, adenovirus; miR, microRNA; scr, scrambled; SCC, squamous cell carcinoma; SV-sHEK, simian virus 40 large T antigen-transformed human epidermal keratinocytes; FB, dermal fibroblasts; MC, melanocytes. 
A

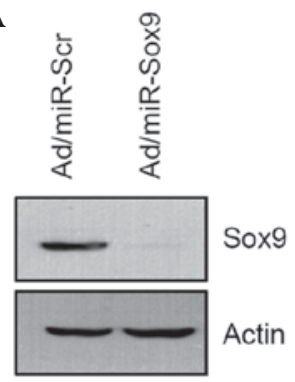

B

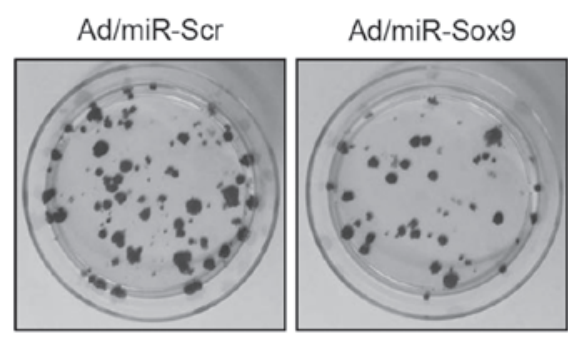

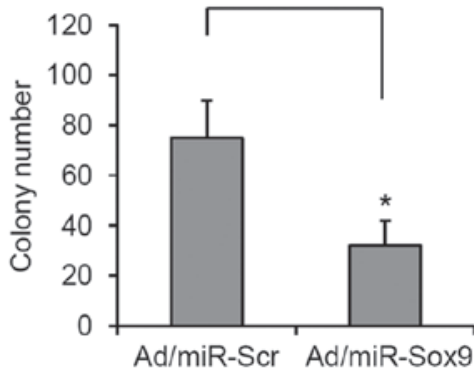

Figure 3. Decreased colony-forming activity in SCC1 cells as a result of Sox9. (A) SCC12 cells were transduced with Ad expressing miR-Sox9. Western blotting demonstrated effective knockdown of Sox9. (B) Following Ad transduction, a colony-forming assay was performed. Knockdown of Sox9 decreased colony-forming activity of SCC12 cells. Colonies were counted. The data are expressed as the mean \pm standard deviation $\left(\mathrm{n}=3\right.$; $\left.{ }^{*} \mathrm{P}<0.01\right)$. Ad, adenovirus; miR, microRNA.
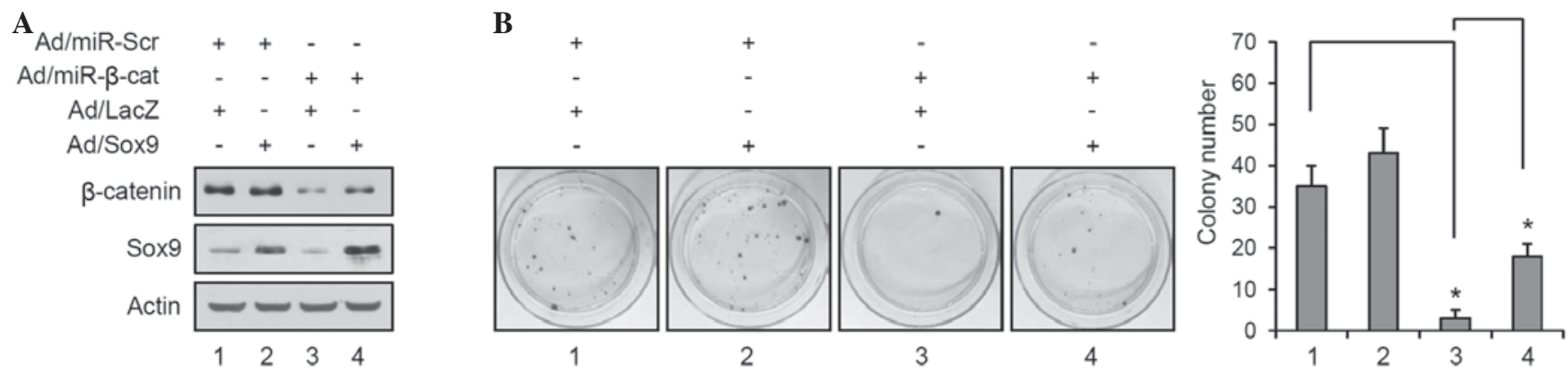

Figure 4. Restoration of colony-forming activity of $\beta$-cat-knockdown cells by Sox9. (A) SCC12 cells were co-transduced with Ad expressing miR specific for $\beta$-cat and Sox9-overexpressing adenovirus. The expression levels of $\beta$-cat and Sox 9 were detected by western blotting. (B) Following Ad transduction, colony-forming assays were performed. Overexpression of Sox 9 restored the colony-forming activity of $\beta$-cat-knockdown cells. The colonies were counted. The data are expressed as the mean \pm standard deviation $\left(n=3 ;{ }^{*} \mathrm{P}<0.01\right)$. Ad, adenovirus; miR, microRNA; $\beta$-cat, $\beta$-catenin; Scr, scrambled.

cells, including SV-HEK, fibroblasts and melanocytes, was determined. Although it was not significant, the total $\beta$-catenin level was marginally increased in the SCC12 cells compared with the keratinocytes (Fig. 1B). To confirm the potential role of $\beta$-catenin, clonogenic assays were performed as an in vitro tumorigenic test (19). Following transduction of recombinant adenovirus expressing miR specific for $\beta$-catenin, gene knockdown was confirmed (Fig. 1C). Knockdown of $\beta$-catenin markedly reduced the colony-forming potential of SCC12 cells (Fig. 1D), supporting the pivotal role of $\beta$-catenin in the tumorigenesis of SCC.

The present study next attempted to identify the genes regulated by $\beta$-catenin. To this end, the present study transduced the recombinant adenovirus expressing $\mathrm{N}$-terminal 87-amino acid truncated $\beta$-catenin ( $\mathrm{Ad} / \Delta \mathrm{N} 87-\beta$-cat), a constitutively active form of $\beta$-catenin (20). It was found that Sox 9 was induced by the overexpression of the constitutively active form of $\beta$-catenin. Conversely, knockdown of $\beta$-catenin resulted in downregulation of Sox 9 (Fig. 2A). These results suggested that Sox 9 is a $\beta$-catenin-regulated gene in SCC cells and has a potential role in tumorigenesis. Therefore, the expression of Sox 9 was next determined in cutaneous SCC. Immunohistochemistry and western blotting showed that the expression of Sox 9 was increased in cutaneous SCC tissue compared with normal skin tissue (Fig. 2B and C). Consistent with these data, the relative protein expression level of Sox 9 was significantly increased in SCC12 cells compared with keratinocytes cultured in vitro (Fig. 2D).
The expression of Sox9 was reduced in SCC12 cells using the recombinant adenovirus expressing miR specific for Sox9 (Fig. 3A). The colony-forming potential of SCC12 cells was determined, and the data showed that knockdown of Sox 9 significantly decreased the colony number (Fig. 3B). These results suggested that Sox 9 is a potential transcription factor that can increase tumorigenicity of SCC cells.

To further confirm the association between $\beta$-catenin and Sox $9, \beta$-catenin levels were reduced and the expression of Sox 9 was simultaneously increased using the recombinant adenovirus (Fig. 4A). Overexpression of Sox9 led to a slight increase of colony number in the control miR transduced group, however, it was not significant (lane 1 vs. 2; Fig. 4B). Consistent with previous data, knockdown of $\beta$-catenin resulted in a marked decrease of colony formation; however overexpression of Sox 9 partially restored the colony-forming potential (lane 3 vs. 4; Fig. 4B). These results strengthened the notion that Sox9 is a $\beta$-catenin-downstream transcription factor and is involved in the development of SCC.

\section{Discussion}

In the present study, it was found that Sox 9 was regulated by $\beta$-catenin in SCC12 cells. When $\beta$-catenin signaling was activated by the overexpression of stabilized $\beta$-catenin $(\Delta N 87-\beta-C a t)$, Sox 9 expression was increased. By contrast, knockdown of $\beta$-catenin using specific miR resulted in the downregulation of Sox 9. Sox 9 demonstrated tumorigenicity in 
terms of colony-forming activity . Therefore, the present data suggested that $\beta$-catenin-regulated Sox 9 is one of the effector molecules that can positively affect the development of SCC.

Sox 9 is a member of high mobility group box transcription factor family and serves a critical role in various biological events, including embryonic development, cell fate determination and lineage commitment $(21,22)$. Germline mutation for Sox 9 causes campomelic dysplasia, a disorder characterized by numerous skeletal abnormalities, defects in central nervous system and XY sex reversal $(23,24)$. A potential role of Sox 9 for cancer development has been previously recognized. For example, Sox 9 supports breast tumor cell proliferation and directly contributes to the poor clinical outcomes associated with invasive breast cancer $(25,26)$. In other examples, high levels of Sox 9 were detected in colorectal cancer and Sox 9 exhibits several properties, including the ability to promote proliferation, inhibit senescence and collaborate with other oncogenes in neoplastic transformation $(27,28)$. Based on these findings, it is plausible that Sox 9 can also affect cutaneous SCC development. The present study demonstrated that Sox 9 was increased in cutaneous SCC, and that Sox 9 enhanced the colony-forming activity of SCC12 cells. These data supported the notion that Sox 9 is an important pro-oncogenic protein in SCC development.

The putative association between $\beta$-catenin and Sox 9 has been demonstrated several times in other systems. For example, the Wnt signaling pathway promotes chondrocyte differentiation in a Sox9-dependent manner (29). Another example shows that Sox 9 protein is expressed in the intestinal epithelium in a pattern characteristic of $\mathrm{Wnt} / \beta$-catenin targets. Additionally, inhibition of $\beta$-catenin signaling by the overexpression of dominant negative TCF4 resulted in a marked decrease of Sox9 in human colon carcinoma cells (30). Finally, conditional inactivation of adenomatous polyposis coli, thereby activating $\mathrm{Wnt} / \beta$-catenin signaling in mouse colon, is associated with the induction of Sox 9 expression and initiation of crypt budding (31). In the present study, activation and inactivation of $\beta$-catenin signaling clearly affected Sox 9 expression in a positive manner. Therefore, the present study suggested that Sox 9 is an authentic $\beta$-catenin-downstream transcription factor and exerts its effect as a positive regulator for cutaneous SCC.

In conclusion, the present study demonstrated that Sox 9 is a functional downstream effector of $\beta$-catenin in cutaneous SCC. These findings provided novel insights into the association between $\beta$-catenin and Sox9 in SCC, and may assist with developing novel therapeutic targets for skin cancer in the future.

\section{Acknowledgements}

The present study was supported by the Basic Science Research Program through the National Research Foundation of Korea funded by the Ministry of Education, Science and Technology (grant no. 2012R1A1A1041389).

\section{References}

1. Alam $M$ and Ratner D: Cutaneous squamous-cell carcinoma. N Engl J Med 344: 975-983, 2001.
2. Brash DE, Rudolph JA, Simon JA, Lin A, McKenna GJ, Baden HP, Halperin AJ and Pontén J: A role for sunlight in skin cancer: UV-induced p53 mutations in squamous cell carcinoma. Proc Natl Acad Sci USA 88: 10124-10128, 1991.

3. Kolev V, Mandinova A, Guinea-Viniegra J, Hu B, Lefort K, Lambertini C, Neel V, Dummer R, Wagner EF and Dotto GP: EGFR signalling as a negative regulator of Notch1 gene transcription and function in proliferating keratinocytes and cancer. Nat Cell Biol 10: 902-911, 2008.

4. van Hogerlinden M, Rozell BL, Ahrlund-Richter L and Toftgård R: Squamous cell carcinomas and increased apoptosis in skin with inhibited Rel/nuclear factor-kappaB signaling. Cancer Res 59: 3299-3303, 1999.

5. Brasanac D, Boricic I, Todorovic V, Tomanovic $\mathrm{N}$ and Radojevic S: Cyclin A and beta-catenin expression in actinic keratosis, Bowen's disease and invasive squamous cell carcinoma of the skin. Br J Dermatol 153: 1166-1175, 2005.

6. Lyakhovitsky A, Barzilai A, Fogel M, Trau H and Huszar M: Expression of e-cadherin and beta-catenin in cutaneous squamous cell carcinoma and its precursors. Am J Dermatopathol 26: 372-378, 2004.

7. Doglioni C, Piccinin S, Demontis S, Cangi MG, Pecciarini L, Chiarelli C, Armellin M, Vukosavljevic T, Boiocchi M and Maestro R: Alterations of beta-catenin pathway in non-melanoma skin tumors: Loss of alpha-ABC nuclear reactivity correlates with the presence of beta-catenin gene mutation. Am J Pathol 163: 2277-2287, 2003

8. Hisken J and Behrens J: The Wnt signaling pathway. J Cell Sci 113: 3545-3546, 2000.

9. Zhang Y, Liu B, Zhao Q, Hou T and Huang X: Nuclear localizaiton of $\beta$-catenin is associated with poor survival and chemo-/radioresistance in human cervical squamous cell cancer. Int J Clin Exp Pathol 7: 3908-3917, 2014.

10. Li P, Cao Y, Li Y, Zhou L, Liu X and Geng M: Expression of Wnt-5a and $\beta$-catenin in primary hepatocellular carcinoma. Int J Clin Exp Pathol 7: 3190-3195, 2014.

11. Cui J, Xi H, Cai A, Bian S, Wei B and Chen L: Decreased expression of Sox7 correlates with the upregulation of the Wnt/ $\beta$-catenin signaling pathway and the poor survival of gastric cancer patients. Int J Mol Med 34: 197-204, 2014.

12. Malanchi I, Peinado H, Kassen D, Hussenet T, Metzger D, Chambon P, Huber M, Hohl D, Cano A, Birchmeier W and Huelsken J: Cutaneous cancer stem cell maintenance is dependent on beta-catenin signalling. Nature 452: 650-653, 2008.

13. Popp S, Waltering S, Herbst C, Moll I and Boukamp P: UV-B-type mutations and chromosomal imbalances indicate common pathways for the development of Merkel and skin squamous cell carcinomas. Int J Cancer 99: 352-360, 2002.

14. Choi HI, Sohn KC, Hong DK, Lee Y, Kim CD, Yoon TJ, Park JW, Jung S, Lee JH and Lee YH: Melanosome uptake is associated with the proliferation and differentiation of keratinocytes. Arch Dermatol Res 306: 59-66, 2014.

15. Je YJ, Choi DK, Sohn KC, Kim HR, Im M, Lee Y, Lee JH, Kim CD and Seo YJ: Inhibitory role of Id1 on TGF- $\beta$-induced collagen expression in human dermal fibroblasts. Biochem Biophys Res Commun 444: 81-85, 2014.

16. Lee JS, Kim DH, Choi DK, Kim CD, Ahn GB, Yoon TY, Lee JH and Lee JY: Comparison of gene expression profiles between keratinocytes, melanocytes and fibroblasts. Ann Dermatol 25: 36-45, 2013.

17. Sohn KC, Shi G, Jang S, Choi DK, Lee Y, Yoon TJ, Park H, Hwang C, Kim HJ, Seo YJ, et al: Pitx2, a beta-catenin-regulated transcription factor, regulates the differentiation of outer root sheath cells cultured in vitro. J Dermatol Sci 54: 6-11, 2009.

18. Shi G, Sohn KC, Li Z, Choi DK, Park YM, Kim JH, Fan YM, Nam YH, Kim S, Im M, et al: Expression and functional role of Sox9 in human epidermal keratinocytes. PLoS One 8: e54355, 2013.

19. Franken NA, Rodermond HM, Stap J, Haveman J and van Bree C: Clonogenic assay of cells in vitro. Nat Protoc 1: 2315-2319, 2006.

20. Gat U, DasGupta R, Degenstein L and Fuchs E: De Novo hair follicle morphogenesis and hair tumors in mice expressing a truncated beta-catenin in skin. Cell 95: 605-614, 1998.

21. Lefebvre V, Dumitriu B, Penzo-Méndez A, Han Y and Pallavi B: Control of cell fate and differentiation by Sry-related high-mobility-group box (Sox) transcription factors. Int J Biochem Cell Biol 39: 2195-2214, 2007.

22. Sarkar A and Hochedlinger K: The sox family of transcription factors: Versatile regulators of stem and progenitor cell fate. Cell Stem Cell 12: 15-30, 2013. 
23. Foster JW, Dominguez-Steglich MA, Guioli S, Kwok C, Weller PA, Stevanović M, Weissenbach J, Mansour S, Young ID, Goodfellow PN, et al: Campomelic dysplasia and autosomal sex reversal caused by mutations in an SRY-related gene. Nature 372: 525-530, 1994

24. Schafer AJ, Foster JW, Kwok C, Weller PA, Guioli S and Goodfellow PN: Campomelic dysplasia with XY sex reversal: Diverse phenotypes resulting from mutations in a single gene. Ann NY Acad Sci 785: 137-149, 1996.

25. Chakravarty G, Moroz K, Makridakis NM, Lloyd SA, Galvez SE, Canavello PR, Lacey MR, Agrawal K and Mondal D: Prognostic significance of cytoplasmic SOX9 in invasive ductal carcinoma and metastatic breast cancer. Exp Biol Med (Maywood) 236: 145-155, 2011.

26. Wang H, He L, Ma F, Regan MM, Balk SP, Richardson AL and Yuan X: SOX9 regulates low density lipoprotein receptor-related protein 6 (LRP6) and T-cell factor 4 (TCF4) expression and Wnt/ $\beta$-catenin activation in breast cancer. J Biol Chem 288 : 6478-6487, 2013.

27. Matheu A, Collado M, Wise C, Manterola L, Cekaite L, Tye AJ, Canamero M, Bujanda L, Schedl A, Cheah KS, et al: Oncogenicity of the developmental transcription factor Sox9. Cancer Res 72: 1301-1315, 2012.
28. Panza A, Pazienza V, Ripoli M, Benegiamo G, Gentile A, Valvano MR, Augello B, Merla G, Prattichizzo C, Tavano F, et al: Interplay between SOX9, $\beta$-catenin and PPAR $\gamma$ activation in colorectal cancer. Biochim Biophys Acta 1833: 1853-1865, 2013

29. Yano F, Kugimiya F, Ohba S, Ikeda T, Chikuda H, Ogasawara T, Ogata N, Takato T, Nakamura K, Kawaguchi H and Chung UI: The canonical Wnt signaling pathway promotes chondrocyte differentiation in a Sox9-dependent manner. Biochem Biophys Res Commun 333: 1300-1308, 2005.

30. Blache $\mathrm{P}$, van de Wetering $\mathrm{M}$, Duluc I, Domon C, Berta P, Freund JN, Clevers H and Jay P: SOX9 is an intestine crypt transcription factor, is regulated by the Wnt pathway, and represses the CDX2 and MUC2 genes. J Cell Biol 166: 37-47, 2004.

31. Feng Y, Sentani K, Wiese A, Sands E, Green M, Bommer GT, Cho KR and Fearon ER: Sox9 induction, ectopic Paneth cells, and mitotic spindle axis defects in mouse colon adenomatous epithelium arising from conditional biallelic Apc inactivation. Am J Pathol 183: 493-503, 2013. 